\title{
One-Block-Building Design for Rayon Staple Spinning Mill
}

\author{
By Giichi Takamasa \\ Director and General Manager, \\ Ogaki Spinning Mill, Toho Rayon Co., Ltd.
}

\section{Introduction}

In the planning of a spinning mill, the quality, cost and productivity of yarn are obviously considerations of basic importance. Yarn of superior quality makes for efficient spinning; it is impossible to obtain the same efficiency with yarn of inferior quality. This axiom can be termed "productivity through quality-control".

Problems involved in productivity through quality-control include selection of a mill site, quality of equipment and raw materials, etc. The most up-to-date machinery is unquestionably needed for rayon staple spinning; and control of humidity is essential for efficient operations.

Low cost of yarn production is achieved simply by reducing labor cost and increasing production per spindle. In Japan, where interest on operating capital is high, cost of production cannot be lowered unless output per spindle is increased.

Therefore, in order to produce low-cost and high-quality yarn, the aformentioned requisites should be fulfilled in the construction of a spinning mill.

Our Ogaki Spinning Mill is designed with full attention paid to these requisites. The salient features of the mill are:

(1) It is an earthquake-proof and fire-proof structure of steel and concrete, complete with a business office, storage facilities, an air conditioning room, a foundry, a workshop, an electric power generating room, etc. This so-called "one-block-building" economizes space and facilitates production control.

(2) The concrete roof is surmounted with a slate roof, thus forming a double roof. Interior walls are coated with heat-resistant Hilcon plaster. Windows have double panes for airtightness and heat resistance, to facilitate humidity control.

(3) There are no partitions from carding to finishing; the whole place is one big working area. which facilitates transportation and control. (4) For humidity control, clear well-water is used in air-conditioning. Spraying, steaming and watering are done away with.

(5) Spinning operations have been abbreviated as far as is feasible without lowering the quality of yarn; and a modified large-package system is adopted to meet conditions peculiar to Japan. (6) Remote control of power and equipment is employed as for as possible.

One result of these features of the mill has been that our production per spindle per 16 net hours exceeds $0.7 \mathrm{lb}$. of $30^{\prime} \mathrm{s}$.

\section{Construction}

Air-tight and heat-resistant construction is more important to rayon staple than to cottcn.

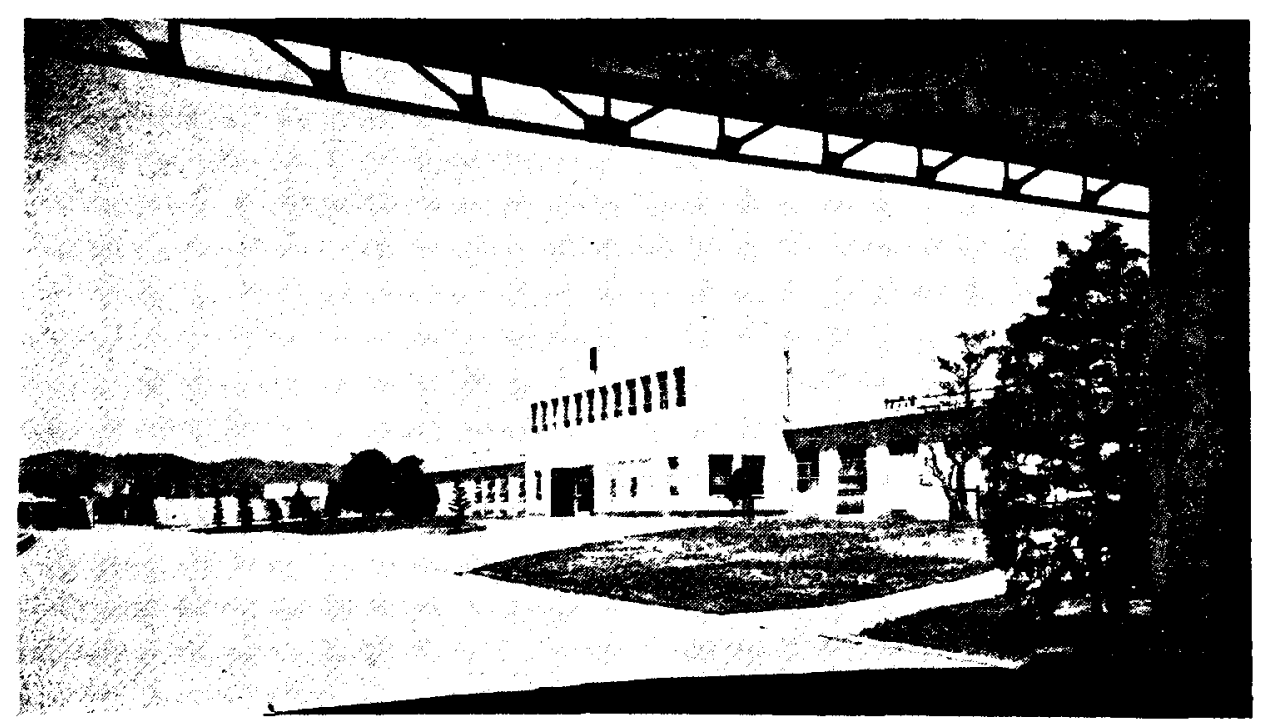

Fig. 1 Front view of the Ogaki Spinning Mill. 


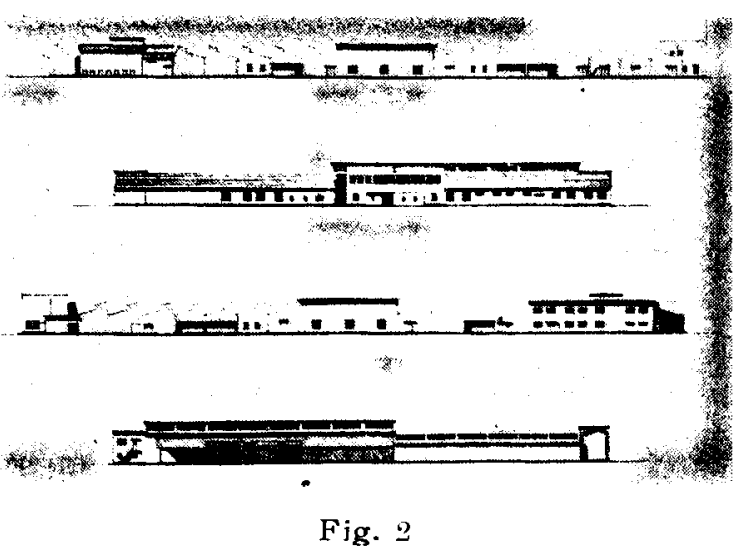

Side-elevations of the Ogaki Spinning Mill.

The sensitivity of rayon staple to the influences of surrounding humidity and temperature is well known. Consequently, it is hardly necessary to emphasize further the importance of humidity control.

However, in a single large room it is difficult to achieve uniform humidity to match theoretical requirements. Although uniformity may seem. to be indicated apparently, it is difficult to obtain uniformity of effective humidity in practice, because of the location of machinery as well as differences in the degree of pressure caused by air circulation induced by machine revolutions.

The wet-and-dry-bulb hygrometer, used in m.cst cases to measure relative humidity, is considered an imperfect gauge. (According to Oldenburg, in extreme cases the hygrometer shows an error of $16 \%$.) So there are often cases where humidity conditions cannot be known accurately. In view of this shortcoming, particular attention was paid, in the construction of our mill, to avoiding unnecessary movement of air, and to securing heat-resistance and air-tightness.

In the past, spinning mills in Japan have been constructed with offices, storage units, repair shops and other workshops apart from the spinning room; and these were connected by long corridors. Such a layout must be regarded as uneconomic and inefficient. To eliminate these shortcomings, we designed the oneblock-building, in which the main spinning area is kept within a minimum of space, thus saving cn corridors and walls, and also providing convenient connection between offices and working areas.

In this type of layout, also, there are double walls which completely cut cff the spinning area from out-door air. (See Fig. 3.) While this structure offers the enormous advantages already explained, it makes a further expansion of the main spinning room difficult.

The insides of exterior walls and ceilings, as

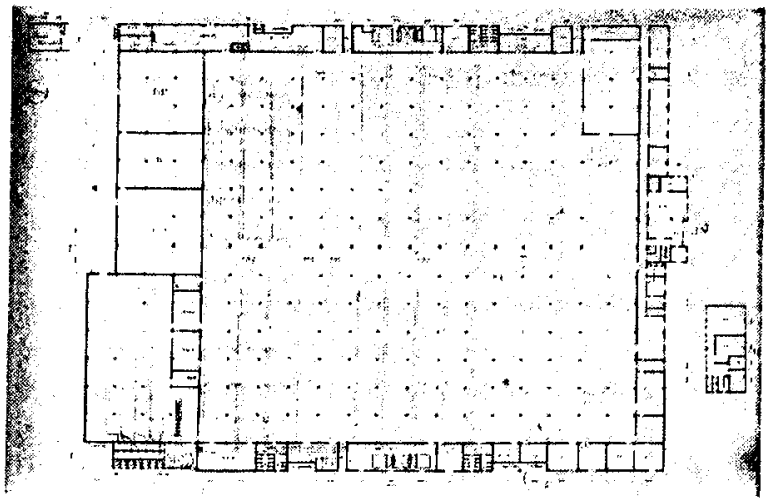

Fig. 3

Location of equipment, the Ogaki Spinning Mill.

well as the space between ducts in the ceiling, are concrete-finished and coated with about 5 inch of heat-resistant Hilcon plaster, to form complete protection against heat and outdoor air.

As shown in Figure 4, the beams of the concrete roof protrude outward. Purlins are fixed on them to carry a sheathing of roof board, which is covered, in turn, with corrugated asbestos slate. This forms a double rcofing, which prevents rain leakage and insures effective heat resistance. The inside of the whole ceiling is also treated with Hilcon plaster.

The roof contains an air-space in which run the carrier ducts for the air conditioning system. Air exhaust vents are located as high as possible, to eliminate uneven air conditions. The ceiling is entirely plain so that lighting will not be distorted.

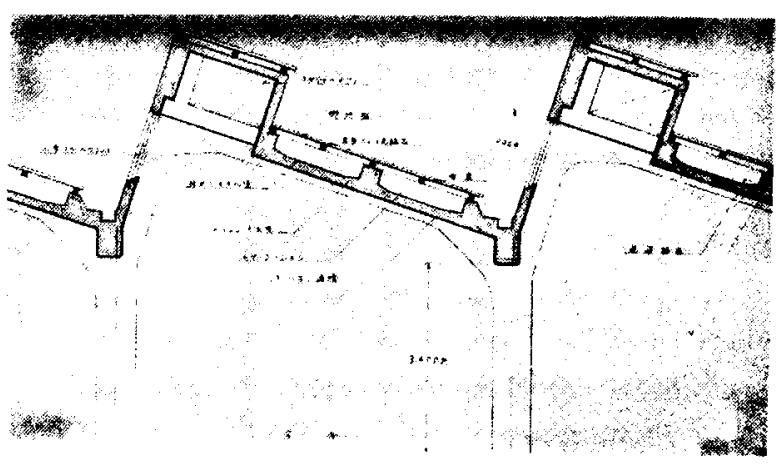

Fig. 4 Sectional diagram of ceiling and roof.

In recent years there have been many window-less spinning mills built. However, windows are a natural accessory to the human dwelling in a general sense; for a "human tcuch" we have provided windows to create a pleasant atomosphere within the spinning area. The interior is of wire-net glass, the exterior of thick plate glass, both permanently fixed.

Only the blowing rocm is sectioned off; other operations are done in a single rcom to save on labor. (See Fig. 3.) 


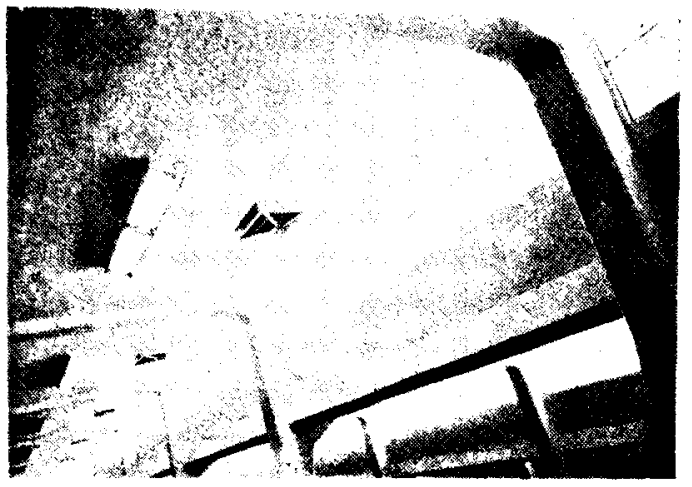

Fig. 5

Skylight and ventilator, the Ogaki Spinning Mill.

The dormitory, hospital, school and employees' housing were all built in precon (pre-cast concrete) style under the supervision of the late Dr. H. Tanabe, a prominent architect. All structures are assembled from pre-fabricated sections. These can be erected more quickly than ordinary concrete buildings, and are quakeresistant and fire-proof. Furthermore, there is a saving in materials and labor, and relocation of buildings is easier.

\section{Installation of Machinery}

These are a few special features:

(1) Power is remote-controlled for the whole operation. The initial cost is greater, but it is economical in the long run, since there is a saving in labor and greater safety and convenience in operation.

(2) In view of economic conditions in Japan, a modified large-package system is used throughout the operation. It would be uneconomical to use the large-package system common in the U.S.A.

We experimented by spinning $40 / 2$, with a $3 \frac{1}{2}$ inch diameter ring, and calculated costs based on depreciation and interest on the building, machinery, etc. We found that the American system would be economical only when a girl worker's monthly wage reached 36,000 Yen (as against the present average of 7,060 Yen). The paradox of high interest and low cost of labor is the basic problem in Japan, one which stands in the way of efficient management at present.

- (3) Natural fibers like cotton are uneven in length, yet they can be processed smoothly on a simplex fly frame. But the roving is not suitable for spinning.

Rayon staple is long, and the evenness of fibers gives less trouble; therefore the D. S. simplex is suitable and the fibers show better cohesion. As several improvemens have been made in the D.S. simplex roving frame, this machine is considered suitable for the abbrevi- ated process of rayon staple spinning.

In the U.S. A. spinning of rayon staple on the worsted system has been simplified by skilful use of long-draft roving frames. The quality and efficiency of yarn are greatly affected by the use of either sliver or roving (slightly twisted) for spinning. Because of the problems of draft and cohesion of fibers, we consider it important to use twisted roving.

(4) We have simplified the precess as much as possible, until it now consists of two passages for drawing, slubbing on D.S. simplex, spinning by super-high-draft system. The crimp and elasticity of crimped rayon staple are most subject to adverse effects in the process of drawing and slubbing. Therefore, every manufacturer must give carful consideration to the number of machines used.

(5) In order to make maximum use of the characteristic qualities of rayon staple, four-line high-draft machinery with roving is used. Because of the evenness of the length of manmade fibers, high-draft is possible. In drafting, it is necessary, above all, to avoid scattering and destroying the cohesion of the fibers.

Where quality and spinnability of yarn can be maintained efficiently, the super-high-draft system is most useful.

The length of rayon staple can be changed easily. For instance, when a 2-inch fiber is made $\frac{1}{4}$ inch longer, the capacity per spindle can be increased by $10 \%$. Coarse fibers such as 3 or 5 denier can be spun using longer fibers efficiently and economically.

(6) In order to reduce power consumption per spindle and to obtain smooth running, we use S. K. F. roller bearing inserts. It is thus possible to save about $15 \%$ on power; and even for higher speeds, a $10 \mathrm{HP}$ motor is quite sufficient, subject to careful handing.

(7) As already mentioned, we have designed our mill in such a way as to economize on the control of humidity as much as possible.

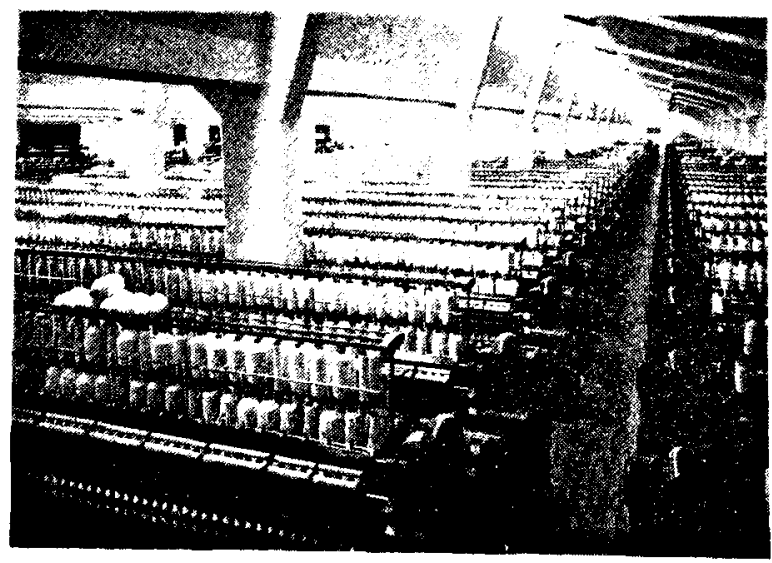

Fig. 6 Interior of the spinning area. 
In rayon staple spinning, the moisture content of the raw material affects considerably the efficiency and operation of the whole process.

In other mills, moisture is added, and this requires space, labor and expense. Our milldoes not use a direct spray on the raw material. In the blowing rcom. while the rayon staple is passing through the machinery, controlled humidity is automatically fed evenly to the fibers. For use solely in the blowing room, a specially controlled humidity carrier system is provided. Purified air is sent through underfloor ducts and blown into the heart of the machinery, so that water content may be increased gradually to obtain a lap with uniform moisture content.

At the same time, the blowing rcom itself is kept under controlled humidity, and seasoning of unbaled rayon staple occurs in abcut 24 hours.

With direct spray, it is difficult to achieve evenness of moisture content, and more space and labor are required. But by our method, labor is reduce by half and space to a minimum.

\begin{tabular}{ccccccc}
$\begin{array}{c}\text { Room } \\
\text { humidity }\end{array}$ & \multicolumn{2}{c}{$\begin{array}{l}\text { Staple water } \\
\text { content before } \\
\text { feeding }\end{array}$} & \multicolumn{3}{c}{$\begin{array}{l}\text { Lap water } \\
\text { content }\end{array}$} \\
& $\frac{X}{X}$ & $R$ & $\sigma$ & $X$ & $R$ & $\sigma$ \\
$74 \%-77 \%$ & $10.2 \%$ & 1.99 & 1.00 & $14.25 \%$ & 1.04 & 0.52
\end{tabular}

We aim at $14 \%$ water content in the finished lap, with an average of $4.2 \%$ added. There still is difficulty in perfecting the uniform addition of water. But in our mill we endeavor to standardize the weight of lap, and in accompanying operations there is no further adjustment (i.e., no draft change gear is used). Drying grain of yarn is kept within action line of $3 \pi$.

Variation in the water content of rayon staple is a problem in Japan. If water content were the same as in the U.S. A. and Europe, uniformity in spinning would be achieved more easily, and the quality of yarn wculd be improved.

To summarize: In the blowing operations we minimize labor and space, and we convert rayon staple with a $4 \%$ variation in water content into a lap with only abcut a $1 \%$ variation within a short space of time.

Exclusion of partition walls from both sides of the spinning area may be regarded as a bold departure from conventional practice. But it will be found convenient and advantagecus, when the special nature of rayon staple and allocation of machinery are examined tcgether. With a little care on the part of the personnel in charge of the control, humidity is generally maintained as follows: Near the carding lines, $67 \%$; before spinning, $65 \%$; spinning, $54 \%$; finishing, $63 \%$.

An interesting feature is that on both sides of the line of spinning frames, there is an invisible wall of air.

Once again we emphasize that humidity control as well as water content are factors which influence the quality of yarn and efficiency. It may be difficult to adopt the kind of humidity control which we employ, if it is too costly. We have, however, a plentiful supply of clear water, which can be obtained by a technically simple and inexpensive system.

(8) The water supply comes from three wells dug into an old river-bed. About 1.4 million U. S. gallons of water per day can be pumped out of each well at a small cost in motor-pcwer. The water is potable, its German hardness is 1.55 degrees, temperature is $11 \sim 13^{\circ}$ C. in summer and $13 \sim 15^{\circ} \mathrm{C}$. in winter.

(9) Our raw material is Tovis crimped rayon staple, manufactured at cur Tokushima plant. It is high in spinnability and easier to handle than cotton.

In recent years, coarser denier fiber has been preferred for the prcduction of better fabrics. For this purpose also, longer fibers are used to enhance the quality and efficiency of the yarn, 2 inch, $2 \frac{1}{2}$ inch, or 3 inch fibers being used on the cotton system.

In Germany, long staple similar to $1 \frac{1}{2} \mathrm{~d}$. and up to $60 \mathrm{~mm}$. is reported to be used on the cotton system. In a mill like ours. where a simplified process is used, $1 \frac{1}{2} \mathrm{~d} .60 \mathrm{~mm}$. would be rather difficult to handle, as tco many neps and breaks would occur during scutching and carding. But fibers frcm $3 \mathrm{~d}$. up to $5 \mathrm{~d}$. can be processed better, and it is quite possible to use lengths up to 3 inches.

Yarn made of long fibers of ccarse denier has many neps. Fabrics woven of such yarn appear rcugh, but show better elasticity and hand in finishing. After all, the actual commercial value lies in the fabric itself, and not in the yarn. It is also possible to select the denier of fiber best suited to the required yarn count.

For spinning 3-inch fibers, revolutions are not increased (twist can be lessened); so it is possible to reduce cost and increase production per spindle. In cur experience, in spinning $30^{\prime} \mathrm{s}$ yarn, 3 d. and $5 \mathrm{~d}$. blended, it is possible to cbtain more than $0.7 \mathrm{lb}$. per spindle per 16 hours at 10,000 revolutions. Such capacity is impcssible for short fibers, and there is also a saving of power due to the slower spindle speed. 


\section{Conclusion}

The foregoing is a general outline of our one-block-building design for rayon staple spinning. We have planned it as a model of efficient technique and management.

There may be more improved rayon staple mills built elsewhere in the future. Our hope is that, by presenting this article, we may receive comments and advice which will be of benefit to us.

General description of the Ogaki spinning mill.

1. Site

40.38 acres

2. Buildings

Spinning mill $\cdots \cdots \cdots \cdots \cdots \cdot 177,000$ squar feet

Welfare facilites $\cdots \cdots \cdots 107,000$ squar feet

Auxiliary facilites ….... 28,000 squar feet

3. Equipment (Number of machines)

Spinning frames $\cdots \cdots 101 \cdots 40,208$ spindles (4-line super-high-draft)
Twisting frames $\cdots \cdots 27 \cdots 10,800 \quad$ "

Winding frames ...... 34

Scutchers $\ldots \ldots \ldots \ldots \ldots . .4$

Openers …............ 6

Cards …...............160

Drawing frames $\cdots \cdots 13$

Simplex fly frames $\cdots 12$

Doublers ................ 8

Cone winders ….... 4.

Hank winders …..... 10

Bundling press ......... 2

Packing ................ 1

4. Products

Tovis crimped spun rayon yarn, $30 /-.40 / 2,60 / 2$.

5. Employees (April 1955)

\begin{tabular}{lccc}
\hline & Male & Female & \\
Office & 31 & 1 & \\
Workshops & $\mathbf{8 2}$ & 403 & \\
\hline Total & 113 & 403 & 517
\end{tabular}

